\title{
Methodological Approaches for Assessing Certainty of the Evidence in Umbrella Reviews: a Systematic Review
}

\section{Saranrat Sadoyu \\ Pakchongnana hospital \\ Kaniz Afroz Tanni \\ Auburn University \\ Nontaporn Punrum \\ Chiang Mai University \\ Sobhon Paengtrai \\ Chiang Mai University}

\section{Nai Ming Lai}

Taylor's University

Ammarin Thakkinstian

Mahidol University Faculty of Medicine Ramathibodi Hospital

\section{Surachat Ngorsuraches}

Auburn University

\section{Mukdarut Bangpan}

University College London

Nathorn Chaiyakunapruk ( $\square$ nathorn.chaiyakunapruk@utah.edu )

The University of Utah https://orcid.org/0000-0003-4572-8794

\section{Research}

Keywords: certainty, umbrella review, meta-analysis, intervention, GRADE, credibility assessment

Posted Date: September 14th, 2021

DOI: https://doi.org/10.21203/rs.3.rs-543971/v1

License: (c) (P) This work is licensed under a Creative Commons Attribution 4.0 International License. Read Full License 


\section{Abstract}

Objective: To identify and describe the methodological approaches for assessing the certainty of the evidence in umbrella reviews (URs) of meta-analyses (MAs).

Study Design and Setting: We included URs that included SR-MAs of interventions and non-interventions. We searched from 3 databases including PubMed, Embase, and The Cochrane Library from 2010 to 2020.

Results: 138 URs have been included consisting of 96 and 42 URs of interventions and non-interventions, respectively. Only 31 (32.3\%) of URs of interventions assessed certainty of evidence, in which the GRADE approach was the most frequently used method $(\mathrm{N}=20,64.5 \%)$ followed by creditability assessments $(\mathrm{N}=6$, $12.9 \%)$. Conversely, thirty (71.4\%) of URs of non-interventions assessed certainty of evidence, in which the criteria for credibility assessment were mainly used $(\mathrm{N}=28 ; 93 \%)$. URs published in journals with high journal impact factor (JIF) are more likely to assess certainty of evidence than URs published in low JIFs.

Conclusions: Only one-third of URs that included MAs of experimental designs have assessed the certainty of the evidence in contrast to the majority of the URs of observational studies. Therefore, guidance and standards are required to ensure the methodological rigor and consistency of certainty of evidence assessment for URs.

\section{Introduction}

The number of systematic reviews and meta-analysis (SR-MAs) of interventions have increased dramatically over recent years [1]. Due to the increasing number of SR-MAs, the necessity of compiling and updating evidence from these into one accessible and usable document by an umbrella review (UR) has substantially increased over the last decade [2]. Those SRs and MAs may focus on a single treatment comparison and outcome mostly, the UR, also known as overview of reviews, can summarize and even synthesize the findings of all existing treatment regimens and outcomes [1, 2]. As a result, the URs are considered as the source of the highest level of evidence in biomedical literature [2].

Although some methodological standards for SR-MAs can also be applied to URs (e.g., search strategy, study selection, data extraction, etc.) the methods used to assess the certainty of the evidence in the URs are different. In addition, URs are more heterogenous than original SR-MAs because not only they address a wider range of questions but also a variety of the assessment methods has been used to establish the evidence. For instance, some URs use the Grading of Recommendations, Assessment, Development and Evaluations (GRADE) approach, which was originally designed for assessing the certainty of evidence of primary studies included in SRs, not the UR [3]. According to this approach, the certainty is rated ambiguously due to limitations in several domains, e.g., risk of bias, indirectness of evidence, heterogeneity, and imprecision or publication bias. Some URs used the criteria from Physical Activity Guidelines Advisory Committee (PAGAC) to grade the evidence based on applicability, generalizability, risk of bias or study limitations, quantity, consistency (of the results across the available studies), and magnitude and precision of effect sizes [4-6]. Additionally, some URs reported the certainty of the included SRs and MAs as originally reported from each study without further assessment [7-9]. Aromataris et al. [10] also developed and published a methodological guidance focusing on conducting and reporting an umbrella review, but not uncertainty of evidence of UR. 
Furthermore, the UR of SR-MAs is more challenging as they usually report summary statistical data as one of the objective criteria to grade the certainty of evidence. Recently, the relatively strict criteria for stratifying evidence using several statistical parameters (i.e., p-value, predictive interval, small-study effects, and excess significance bias) have also been used and suggested as the good practical tips for conducting good URs [2]. To our knowledge, no formal guidance for assessing the certainty of evidence in URs exists. Therefore, this study aims to identify and describe the methodological approaches for assessing the certainty of the evidence in published URs.

\section{Methods}

This systematic review was conducted according to the methods pre-specified in a registered protocol (PROSPERO registration: CRD42020203273).

\section{Search strategy and selection criteria}

We searched three databases including PubMed, Embase, and The Cochrane Library from May 2010 to May 2020. The keyword 'umbrella review' was used. The full search strategies without language restriction are described in Supplement 1. Manual searches of the reference lists of the eligible articles were also performed. We defined an UR as the review that is designed to summarize the evidence from multiple SR-MAs that were labeled as 'umbrella review' in the title or abstract of the article.

At least two reviewers (SS, KT, NP, SN, and SP) independently reviewed the titles, abstracts, and full texts for their potential inclusion against the eligibility criteria. Any disagreement was resolved by consensus with a third reviewer (NC). URs, overview of SR-MAs, review of SR-MAs were selected if they were (a) URs of MAs of intervention or therapy and (b) URs of MAs of non-intervention or therapy. First, we broadly categorized the retrieved URs into two separate categories- (a) UR of meta-analyses of intervention or therapy and (b) UR of metaanalyses of non-intervention or therapy. For the first category, we included URs into this study if they included MAs of experimental designs (i.e., randomized controlled trials (RCTs) and non-RCTs) that focused on the pooling effect sizes of interventions in prevention or treatment purpose. These interventions could be any of drugs, surgical techniques, changes in treatment/diet/policy, counseling, and modifiable risk factors (for examplesmoking, alcoholism, substance abuse etc.). Again, the second category included those URs of MAs of nonintervention studies involving diagnostic/risk/prognostic factors of diseases or health conditions, disease etiology, prevalence or incidence; in which most studies were observational studies, e.g., cohort, case-control, and cross-sectional studies [11].

Other types of studies or reviews (e.g., handbooks, guidelines, commentaries, editorials, and methodological studies), materials for poster presentations, URs with network MAs, UR of SRs without MAs, and protocols of URs were excluded.

\section{Data extraction}

At least two of five reviewers (SS, NP, SN, KT, and SP) independently extracted the data from each UR into a customized data extraction table. Any disagreement was resolved by consensus with a third reviewer (NC). Details of data extraction are described in Supplement 2. 
The assessment of the certainty of evidence was defined as any of evaluation of the totality or strength of the evidence such as the GRADE approach, criteria for credibility assessment, Agency for Healthcare Research and Quality (AHRQ) methods for systematic review, and other approaches used to grade the overall body of the UR evidence.

\section{Data synthesis and analysis}

A descriptive analysis of the methodological approaches for assessing the certainty of evidence in the URs was performed by frequencies and percentage stratified by intervention and non-intervention URs. The included URs were classified into high and low impact sources based on the journal impact factors (JIF) reported by the Institute of Scientific Information's Journals Citation Report in 2019 [12]. The journals reported as the top 100 highest ranking for the therapeutic and non-therapeutic fields were defined as the high, otherwise they were classified as low impact groups. In addition, we also classified based on a median JIF, i.e., high if the URs were published in JIF $\geq$ median, otherwise the URs were classified as lower impact groups. When feasible, we further compared URs published between 2010-2015 with those published from 2016 to 2020. Chi-square or Fisher's exact test where appropriated was applied to compare characteristics of URs between groups. All analyses were performed using STATA version 15.0 (College Station, TX), p-value $\leq 0.05$ was considered as statistical significance. We analyzed data and presented the results separately for two aforementioned categories of URs (URs of MA of intervention studies and URs of MA of non-intervention studies).

\section{Results}

\section{Search results}

We identified 1767 articles, of which 174 and 1282 articles were excluded due to duplicates and during screening titles/abstracts, respectively: leaving 311 studies for the full-text review. A total of 138 URs matched with the eligibility criteria and were finally included in our study (Fig. 1). Among them, 96 and 42 were URs for interventions and non-interventions $[5,6,8,9,13-146]$, respectively. The reasons for exclusion of the 173 articles after full-text review were described in detail in Supplement 3.

\section{Characteristics of included URs}

Table 1 and Supplement 4 summarize the characteristics of the 96 URs of SR-MAs of interventions. The number of URs increased over time from 1 in 2011 to 20 in 2020, with the majority being published in the recent 5 years (2016-2020), $(N=85,88.5 \%)$. Forty-five (46.9\%) included only SR-MAs of RCTs whereas the rest URs mixed SRMAs of RCTs and non-RCTs. A median number of included SR-MAs in URs was 7 (Interquartile range (IQR): 2-21). Forty-five URs reported the number of primary studies included in MAs with a median of 123 primary studies (IQR: $20-255)$. Only 5 URs $(5.2 \%)$ were classified into high impact group $[61,71,119,128,146]$. The median of JIF was 2.74 (IQR: 1.92-4.05). 
Table 1

Description of included umbrella reviews

\section{Description}

Response, $n$ (\%)

UR of intervention

studies $(n=96)$

Year published

2011-2015

2016-2020

Number of meta-analysis included in URs, median (IQR)

Number of primary studies included in meta-analysis median (IQR)

Number of study participants, range

Journal impact factor (IF), median (IQR)
$11(11.5)$

$85(88.5)$

$7(2-21)$

$128(20-255)$

46 to 992,129

$2.74(1.91-$

4.08)
UR of noninterventional studies $(n=42)$

Journal publication

Published in High impact groups (Top 100 journal impact factor)

Published in lower impact groups

$5(5.2)$

$6(14.3)$

$91(94.8)$

$36(85.7)$

Characteristics of Included URs

URs with meta-analysis of only RCTs

45 (46.9)

NA

URs with meta-analysis of RCTs and other experimental studies

$51(53.1)$

NA

Assessment of the certainty of the evidence

Performed by umbrella review authors

$31(32.3)$

$30(71.4)$

Not performed by umbrella review authors

$12(28.6)$

- Reported the certainty level as originally reported from the included SR/MA

2

12

Tools used for assessing certainty of the evidence $(n=31)$

GRADE approach

$14(7)$

Criteria for credibility assessment

$6(12.9)$

$28(93)$

(2 studies performed both credibility assessment and GRADE)

2018 Physical Activity Guidelines Advisory Committee (PAGAC) Recommendations

Other tools

Author's own tools

Methodological quality assessment

Performed by umbrella review authors

2 (6.5) NA

$3(9.7)$

NA

$2(6.5)$

NA
$41(97.6)$

(2.4)

31(17-61)

388 (54-1354)

1 to $225,000,000$

4.99 (2.49-8.31) 


\begin{tabular}{|c|c|c|}
\hline \multirow[t]{2}{*}{ Description } & \multicolumn{2}{|l|}{ Response, $n(\%)$} \\
\hline & $\begin{array}{l}\text { UR of } \\
\text { intervention } \\
\text { studies }(n=96)\end{array}$ & $\begin{array}{l}\text { UR of non- } \\
\text { interventional } \\
\text { studies }(n=42)\end{array}$ \\
\hline Not performed by umbrella review authors & $12(12.5)$ & $16(38.1)$ \\
\hline Tools used for assessing methodological quality & $(n=84)$ & $(n=26)$ \\
\hline AMSTAR & $40(47.6)$ & $13(50)$ \\
\hline AMSTAR 2 & $13(15.5)$ & $6(23.1)$ \\
\hline JBI critical appraisal checklist for SRs & $6(7.1)$ & $6(23.1)$ \\
\hline ROBIS & $4(4.8)$ & NA \\
\hline Modified AMSTAR (e.g., AMSTARExBP) & $3(3.6)$ & NA \\
\hline $\begin{array}{l}\text { Critical appraisal tool for systematic reviews based on Centre for } \\
\text { Evidence-Based Medicine (CEBM) recommendations }\end{array}$ & $3(3.6)$ & NA \\
\hline Methodological Quality Checklist (MQC) & $3(3.6)$ & NA \\
\hline $\begin{array}{l}\text { Oxman and Guyatt Overview Quality Assessment Questionnaire } \\
\text { (OQAQ) }\end{array}$ & $3(3.6)$ & NA \\
\hline Other tools & $9(10.7)$ & $1(3.8)$ \\
\hline - NIH Quality Assessment tool & 2 & NA \\
\hline - PRISMA 2009 Checklist quality assessment tool & 2 & NA \\
\hline - Scottish Intercollegiate Guidelines Network (SIGN) tool & 2 & NA \\
\hline $\begin{array}{l}\text { - The tool for assessing quality of meta-analyses described by } \\
\text { Higgins and colleagues }\end{array}$ & 1 & NA \\
\hline $\begin{array}{l}\text { - The Critical Appraisal Checklist for Systematic Reviews developed } \\
\text { by the Umbrella Review Methodology Working Group (Aromataris et } \\
\text { al) }\end{array}$ & 1 & NA \\
\hline - Author's own criteria & 1 & NA \\
\hline - Newcastle Ottawa Scale & NA & 1 \\
\hline
\end{tabular}

The characteristics of 42 URs of SR-MAs of non-interventions are also summarized in Table 1 and Supplement 4 [13-54]. All except 1 URs were published between 2010-2015. Most URs (88.1\%) were conducted on SR-MAs of analytic observational studies evaluating etiology, diagnostic/prognostic biomarkers, or other non-modifiable risk factors of a disease or health condition, the remaining URs focused on disease prevalence/ incidence (7.1\%), risk prediction models (4.8\%). The median number of MAs included in these corresponding URs were 31 (IQR: 17-61), The median of total number of primary studies included were 388 (IQR: 54-1354). Six of the 42 URs (14.3\%) were published in high impact factor journals. The median JIF was 4.99 (IQR: 2.49-8.31).

\section{Methodological approaches for assessing certainty of the evidence}


Of 96 URs of SR-MAs of interventions, only 31 (32.3\%) assessed the certainty of the evidence, see Table 1. GRADE approach was the most frequently used method for assessing the certainty of the evidence $(N=20,64.5 \%)$ followed by credibility assessments $(N=6,12.9 \%)$, see Fig. 2. Criteria for the credibility assessment were varied across studies, as shown in Table 2. For instance, convincing evidence was graded based on the number of cases included in each MA of $\geq 350$ to $\geq 5000$ or p-values of $<10^{-6}$ or even $<0.001$. Of five URs published in highimpact journal group $[61,71,119,128,146]$, the assessment of certainty of the evidence was performed in three studies using GRADE approach and criteria for credibility assessment. Compared with the other two URs [61, 71] that did not assess the certainty of the evidence, these three studies were published more recently (published in 2019-2020 compared with 2014-2016). Table 3 showed the certainty and methodological quality assessment in URs. Based on the median of JIF, the percent URs that assessed the certainty of evidence was significantly higher in in the high impact group (IF > 2.74) than the lower impact group (IF $\leq 2.74$ ), i.e., 44.7\% vs 20.4\%, $p=0.01$. Comparing the period of 2016-2020 with 2010-2015, the percent URs with certainty of the evidence assessments was significantly higher in a period of $2016-2020$ than $2010-2015(36.5 \%$ vs $n=0 \%, p=0.02)$. 
Table 2

Details of credibility assessment criteria used in umbrella reviews published in higher impact factor journals Details of criteria Criteria for credibility assessment of each study

\begin{tabular}{|c|c|c|c|c|c|}
\hline $\begin{array}{l}\text { Dragioti } \\
\text { E, }\end{array}$ & Dragioti E, & $\begin{array}{l}\text { Chakranon } \\
\text { P. } 2019 \text { (114) }\end{array}$ & Kim JY, & Dinu $M$, & Barbui C, \\
\hline $\begin{array}{l}2017 \\
(73)\end{array}$ & $2018^{(90)}$ & & $2019(120)$ & $2020^{(131)}$ & $2020(128)$ \\
\hline
\end{tabular}

1. Number of categories

(label used)
4

(Class I- (convincing, (convincing,

IV)
5

highly
suggestive,
suggestive,
weak,
no
evidence)

3

(convincing, suggestive,

\section{highly}

suggestive,

suggestive,

weak)

weak

evidence)
5

(convincing,

highly

suggestive, suggestive,

weak,

no evidence)
5

(convincing,

highly suggestive, suggestive, weak,

nonsignificant association)

2. Details of each

category

2.1

Convincing/class

I

$\begin{array}{lllllll}\text { Number of cases } & >1000 & >350 & >1000 & >1000 & \geq 5000 & >1000 \\ \text { P-value } & \mathrm{P}<10^{-6} & \mathrm{P}<10^{-6} & \mathrm{P}<0.001 & \mathrm{P}<0.001 & \mathrm{P} \leq 0.001 & \mathrm{P}<10^{-6}\end{array}$

95\% prediction Used Used Used used Used

interval excluded

null

\begin{tabular}{lllllll} 
Heterogeneity & $\mathrm{I}^{2}<50 \%$ & $\mathrm{I}^{2}<50 \%$ & $\mathrm{I}^{2}<50 \%$ & $\mathrm{I}^{2}<50 \%$ & $\mathrm{I}^{2}<50 \%$ & $\mathrm{I}^{2}<50 \%$ \\
$\begin{array}{l}\text { No evidence of } \\
\text { small-study } \\
\text { effects }\end{array}$ & Used & Used & Used & Used & Used & Used \\
$\begin{array}{l}\text { No evidence of } \\
\text { excess } \\
\text { significance bias }\end{array}$ & Used & Used & Used & Used & Not used & Used \\
$\begin{array}{l}\text { Largest study } \\
\begin{array}{l}\text { with statistically } \\
\text { significant effect }\end{array}\end{array}$ & $\begin{array}{l}\text { Not } \\
\text { used }\end{array}$ & $\begin{array}{l}\text { Used } \\
(\mathbf{P}<\mathbf{0 . 0 5})\end{array}$ & Not used & Not used & Not used & Not used \\
\hline
\end{tabular}

\subsection{Highly}

suggestive/class

II

$\begin{array}{lllllll}\text { Number of cases } & >1000 & >350 & >1000 & \text { No category } & \geq 5000 & >1000 \\ \text { P-value } & P<10^{-6} & P<10^{-6} & P<0.001 & \text { No category } & P \leq 0.001 & P<10^{-6}\end{array}$




\begin{tabular}{|c|c|c|c|c|c|c|}
\hline \multirow[t]{2}{*}{ Details of criteria } & \multicolumn{6}{|c|}{ Criteria for credibility assessment of each study } \\
\hline & $\begin{array}{l}\text { Dragioti } \\
\mathrm{E}, \\
2017 \\
(73)\end{array}$ & $\begin{array}{l}\text { Dragioti E, } \\
2018^{(90)}\end{array}$ & $\begin{array}{l}\text { Chakranon } \\
\text { P, } 2019 \text { (114) }\end{array}$ & $\begin{array}{l}\text { Kim JY, } \\
2019(120)\end{array}$ & $\begin{array}{l}\text { Dinu } M \text {, } \\
2020^{(131)}\end{array}$ & $\begin{array}{l}\text { Barbui C, } \\
2020^{(128)}\end{array}$ \\
\hline $\begin{array}{l}\text { 95\% prediction } \\
\text { interval excluded } \\
\text { null }\end{array}$ & $\begin{array}{l}\text { Not } \\
\text { Used }\end{array}$ & Not Used & Not used & No category & Not Used & Used \\
\hline Heterogeneity & $\begin{array}{l}\text { Not } \\
\text { Used }\end{array}$ & Not Used & $I^{2}<50-75 \%$ & No category & $\begin{array}{l}\text { Not } \\
\text { considerable } \\
\text { heterogeneity } \\
\left(1^{2}=50-75 \%\right)\end{array}$ & Not Used \\
\hline $\begin{array}{l}\text { No evidence of } \\
\text { small-study } \\
\text { effects }\end{array}$ & $\begin{array}{l}\text { Not } \\
\text { Used }\end{array}$ & Not Used & Not Used & No category & Not Used & Not Used \\
\hline $\begin{array}{l}\text { No evidence of } \\
\text { excess } \\
\text { significance bias }\end{array}$ & $\begin{array}{l}\text { Not } \\
\text { Used }\end{array}$ & Not Used & Not Used & No category & Not Used & Not Used \\
\hline $\begin{array}{l}\text { Largest study } \\
\text { with statistically } \\
\text { significant effect }\end{array}$ & $\begin{array}{l}\text { Not } \\
\text { used }\end{array}$ & $\begin{array}{l}\text { Used }(P< \\
0.05)\end{array}$ & Not used & No category & Not used & Not used \\
\hline \multicolumn{7}{|l|}{$\begin{array}{l}2.3 \\
\text { Suggestive/class } \\
\text { III }\end{array}$} \\
\hline Number of cases & $>1000$ & $>350$ & $500-1000$ & Not used & $2500-5000$ & $>1000$ \\
\hline P-value & $\begin{array}{l}P \leq \\
0.001\end{array}$ & $\begin{array}{l}P \geq 10^{-6} \\
\text { but } P< \\
0.001\end{array}$ & $P<0.001$ & $P<0.005$ & $P \leq 0.001$ & $P \leq 0.001$ \\
\hline Heterogeneity & $\begin{array}{l}\text { Not } \\
\text { Used }\end{array}$ & Not Used & $I^{2}>75 \%$ & $I^{2}<50 \%$ & Not Used & Not Used \\
\hline \multicolumn{7}{|l|}{$\begin{array}{l}2.4 \text { Weak/class } \\
\text { IV }\end{array}$} \\
\hline P-value & $P \leq 0.05$ & $P \leq 0.05$ & $P \leq 0.05$ & $P \leq 0.05$ & $P \leq 0.05$ & $P \leq 0.05$ \\
\hline \multicolumn{7}{|l|}{$\begin{array}{l}2.5 \text { Non- } \\
\text { significant }\end{array}$} \\
\hline P-value & $\begin{array}{l}\text { No } \\
\text { category }\end{array}$ & $P>0.05$ & No category & No category & $P>0.05$ & $P>0.05$ \\
\hline
\end{tabular}


Table 3

Certainty and methodological quality assessment in URs of interventions

\begin{tabular}{|lll|}
\hline Study characteristics & Assessment & P-value \\
\hline 1. Performed a certainty assessment & & \\
\hline Classified by the median of impact factor & & \\
\hline Higher impact journals (IF > 2.74) & $21 / 47(44.7 \%)$ & $0.011^{\text {a }}$ \\
\hline Lower impact journals (IF $\leq 2.74)$ & $10 / 49(20.4 \%)$ & \\
\hline Classified by year of publication & & $0.015^{\text {b }}$ \\
\hline 2010-2015 & $0 / 11(0 \%)$ & \\
\hline 2016-2020 & $31 / 85(36.5 \%)$ & \\
\hline 2. Performed a methodological quality assessment & & \\
\hline Classified by the median of impact factor & & \\
\hline Higher impact journals (IF > 2.74) & $40 / 47(85.1 \%)$ & $0.487^{\mathrm{a}}$ \\
\hline Lower impact journals (IF $\leq 2.74)$ & $44 / 49(89.8 \%)$ & \\
\hline Classified by year of publication & & \\
\hline 2010-2015 & & \\
\hline 2016-2020 & & \\
\hline a Chi-square test, ${ }^{b}$ Fisher's exact test. & & \\
\hline
\end{tabular}

Among 42 URs of SR-MAs of non-interventions, 30 (71.4\%) URs performed certainty of evidence assessments based on some assessment tools, while the rest 12 (28.6\%) URs mentioned certainty of the evidence was based on originally reported in the component MAs. Of the 30 URs that assessed certainty of evidence, almost all ( $\mathrm{N}=$ 28; $93 \%$ ) utilized the epidemiological credibility assessment tools. These criteria were followed to assess the evidence base in all but one [44] of the 6 articles in the high impact factor group [15, 24, 39, 44, 46, 47]. The rest of the two URs assessed the certainty of evidence using GRADE criteria.

\section{Methodological quality assessment}

Almost all of the included URs in the intervention group performed the methodological quality assessment of included MAs ( $n=84,87.5 \%)$. Of these, the most frequently used tool was AMSTAR $(n=40,47.6 \%)$, followed by its revised version called AMSTAR $2(n=13,15.5 \%)$, and Joanna Bring Institute (JBI) critical appraisal checklist for SRs $(n=6,7.1 \%)$, as shown in Table 1 and Fig. 2. More details of the methodological quality assessment of included MAs, see Supplement 5-6.

Twenty-six (61.9\%) URs of non-intervention studies have assessed the methodological quality using certain tools, half of which involved AMSTAR while 6 utilized AMSTAR 2, as shown in Table 1. Again, 6 of the URs used critical 
appraisal checklist from the JBI. Only one of the URs that assessed methodological quality used Newcastle Ottawa Scale.

\section{Discussion}

To the best of our knowledge, this is the first study to identify the methodological approaches for assessing the certainty of evidence in URs of that included SR-MAs. Overall, 138 URs have been included consisting of 96 and 42 URs of interventions and non-interventions, respectively. Only one-third of URs of interventions assessed certainty of evidence, in which the GRADE approach was mainly used. URs published in high JIFs are more likely to assess the certainty of evidence than URs published in low JIFs. About two-third of URs of non-interventions assessed certainty of evidence, in which criteria for credibility was mainly used. Nearly $90 \%$ of the URs performed a methodological quality assessment and AMSTAR was the most frequently used tool for this process.

The certainty of the evidence is the extent of confidence to support a decision or recommendation. High certainty in evidence means that the investigators are very confident that the effect they found across studies is close to the true effect and vice versa [147]. Concerning the benefits and harms of a treatment or intervention, the assessment of the certainty of the evidence is essential [148]. Moreover, the certainty of the evidence can be used to develop clinical practice guidelines and recommendations. Again, epidemiological investigations can help establish evidence linking exposure to the incidence of certain health condition in a population. These studies are expected to play a key role in gauging the burden of diseases, delineating guidelines for prevention as well as streamlining the treatment development process. URs of both the interventional and observational studies should aim to provide the highest certainty of evidence to facilitate better health outcomes. Despite the necessity of assessing the certainty of the evidence in URs, there is no consensus that which approach should be the method of choice.

Compared to the results from a previous study by Hartling et al [1] indicating that only $16 \%$ of the overview of reviews published between 2000 and 2011 assessed the certainty of the evidence, our study found that only onethird of included URs of interventional studies assessed the certainty of the evidence. Aligned with the previous study [1], the most frequently used method for assessing the certainty of the evidence in the URs was the GRADE approach. One of the reasons could be that the GRADE approach is a well-established tool developed to determine the certainty of evidence-based on several factors namely risk of bias, imprecision, indirectness, inconsistency, and publication bias [147]. However, this tool was primarily designed for assessing the quality of the evidence from primary studies. Thus, further guidance is needed to ensure appropriate use and interpretation of the GRADE tool when it is applied to assess the quality of evidence of SRs, instead of primary studies [1].

Furthermore, this study demonstrated that several methodological approaches for assessing the certainty of evidence were used in the URs. We found that the criteria for credibility assessment, which was recently released $[10,148]$, was also the second most frequently used method in URs of interventional studies. In contrast, approximately all of the URs of observational studies in our review utilized these epidemiological credibility assessment criteria. The reason that our study differs from the previous study [1,3] likely because we specifically considered the URs that included MAs. The criteria for credibility assessment classified the certainty of the evidence according to several statistical criteria, which usually reported in MA. However, this approach using the arbitrary cut-off values and the cut point of each component in these criteria varied among previously published URs, reflecting the need for guidance. Although Aromataris et al.-a methodology working group formed by the 
JBI (formerly named the URs Working Group)-published the guidance on how to conduct and report an UR [10], the methodology for the certainty assessment was not provided.

This study demonstrated that a higher number of URs with a certainty assessment were published in higher impact journals and the more recent URs tended to assess the certainty of the evidence. One of the reasons could be that the assessment helped to reflect the certainty of results and facilitate the translation of the evidence into guideline recommendations. Therefore, our findings highlighted the importance of guidance for assessing the certainty of the evidence in URs to recommend the most appropriate tools to provide standards for those conducting URs.

This study also demonstrated that majority of the included URs performed a methodological quality assessment. This was more frequent than a previous study [1] that reported the assessment of methodological quality in only $37 \%$ of the overviews of reviews. One of the reasons could be that this process has been strongly recommended in the methodological guidance for producing URs [2] and has been implemented longer than the certainty assessment. This process is essential to ensure that the methodological quality of SR-MAs that included in URs are adequately assessed and incorporated into the results and conclusions. Besides, we found that the most often used tool for methodological quality assessment changed from the Oxman and Guyatt Overview Quality Assessment Questionnaire (OQAQ) to AMSTAR. The AMSTAR tool has been recommended since 2007 and the revised version-AMSTAR 2 was released in 2016. Given that the revised tool introduced recently, the method advocated in published guidance have evolved over time and the variation of tool used for methodological quality assessment reported in this study confirms the need for updated guidance for conducting URs. Furthermore, researchers of URs should incorporate the certainty of evidence and methodological quality assessment and report the results in their URs, which could in turn enable a translation to guideline recommendations or the researchers should otherwise present valid reasons for not assessing it.

Our study has some limitations. First, the definition of included studies was restricted to URs. This might not cover all types of other kinds of reviews for example- overview of reviews, and review of reviews. Therefore, our findings with regards to terminology used to describe "umbrella reviews" and methods used might not be comprehensive or wholly representative. However, there is no universally accepted technical term for this new type of reviews that summarize or synthesize findings from systematic reviews. The term URs has been used increasingly and studies that describe the methodological approach regarding the URs are sparse to date. Second, our study focused on describing the method used in previously published URs and most of them did not provide the reasons for methods selection. Thus, we could not assess the reasons why each UR used different approaches for assessing the certainty of evidence and methodological quality. However, a major strength of our study is that it provides a broad picture of the certainty assessment methods used in URs of both interventional and observational studies. Clearly, authors of URs of observational studies have a preference to use the criteria for credibility assessment tool, while for the URs of experimental studies, the GRADE tool is mostly favored. This highlights an unmet need of a suitable tool to be used in URs of experimental studies. Nevertheless, the reviews of methods used for assessing the certainty of evidence and methodological quality of URs that contained other study designs could be extended in future research.

\section{Conclusions}


This study revealed that only one-third of URs that included MAs of experimental designs have assessed the certainty of the evidence in contrast to the majority of the URs of observational studies. While the most frequently used methodological approach for assessing the certainty of the evidence was the GRADE approach in the first group, epidemiological credibility assessment tool was the dominant method in the later. Therefore, guidance and standards are required to ensure the methodological rigor and consistency of certainty of evidence assessment for URs.

\section{Abbreviations}

AMSTAR: A MeaSurement Tool to Assess systematic Reviews; CEBM: Critical appraisal tool for systematic reviews based on Centre for Evidence- Based Medicine; GRADE: Grading of Recommendations, Assessment, Development and Evaluations; IF: impact factors; IQR: Interquartile range; JBI: Joanna Bring Institute; MA: metaanalysis; MQC: Methodological Quality Checklist; NIH: National Institutes of Health; OQAQ: Oxman and Guyatt Overview Quality Assessment Questionnaire; PAGAC: Physical Activity Guidelines Advisory Committee; RCT: randomized controlled trials; ROBIS: A Risk of Bias Assessment Tool for Systematic Reviews; SIGN: Scottish Intercollegiate Guidelines Network; SR: systematic reviews; ICF: International Classification of Functioning; UR: umbrella review

\section{Declarations}

Acknowledgments: The authors gratefully acknowledge Asst.Prof. Peerawat Jinatongthai for his help on databases searching and search strategy suggestion.

Authors' contributions: SS and NC had the original idea for the study and led the design of the protocol. SS, NP, and SN conducted the literature search and literature screening. SS, KT, NP, SN, and SP extracted data. SS and KT analyzed the data. SS and KT wrote the first draft of the paper. NC supervised the study. NC, NL, AT, SR, and MB reviewed and edited the manuscript. All authors read and approved the final manuscript.

Funding: No funding was received for this work.

Availability of data and materials: The datasets during and/or analyzed during the current study available from the corresponding author on reasonable request.

Ethics approval and consent to participate: Not required.

Consent for publication: Not applicable.

Competing interests: The authors declare that they have no competing interests.

\section{References}

1. Hartling L, Chisholm A, Thomson D, Dryden DM. A descriptive analysis of overviews of reviews published between 2000 and 2011. PloS one. 2012;7(11):e49667. . https://doi.org/10.1371/journal.pone.0049667.

2. Fusar-Poli P, Radua J. Ten simple rules for conducting umbrella reviews. Evid Based Ment Health. 2018;21(3):95-100. https://doi.org/10.1136/ebmental-2018-300014. 
3. Lunny C, Brennan SE, McDonald S, McKenzie JE. Toward a comprehensive evidence map of overview of systematic review methods: paper 2-risk of bias assessment; synthesis, presentation and summary of the findings; and assessment of the certainty of the evidence. Syst Rev. 2018;7(1):159. https://doi.org/ 10.1186/s13643-018-0784-8.

4. Dipietro L, Campbell WW, Buchner DM, Erickson KI, Powell KE, Bloodgood B, et al. Physical Activity, Injurious Falls, and Physical Function in Aging: An Umbrella Review. Med Sci Sports Exerc. 2019;51(6):1303-13. https://doi.org/10.1249/MSS.0000000000001942.

5. Dipietro L, Evenson KR, Bloodgood B, Sprow K, Troiano RP, Piercy KL, et al. Benefits of Physical Activity during Pregnancy and Postpartum: An Umbrella Review. Med Sci Sports Exerc. 2019;51(6):1292-302. https://doi.org/10.1249/MSS.0000000000001941.

6. Kraus VB, Sprow K, Powell KE, Buchner D, Bloodgood B, Piercy K, et al. Effects of Physical Activity in Knee and Hip Osteoarthritis: A Systematic Umbrella Review. Med Sci Sports Exerc. 2019;51(6):1324-39. https://doi.org/10.1249/MSS.0000000000001944.

7. De Freitas L, Goodacre S, O'Hara R, Thokala P, Hariharan S. Interventions to improve patient flow in emergency departments: an umbrella review. Emerg Med J. 2018;35(10):626-37. https://doi.org/10.1136/emermed-2017-207263.

8. Papageorgiou PN, Deschner J, Papageorgiou SN. Effectiveness and Adverse Effects of Deep Brain Stimulation: Umbrella Review of Meta-Analyses. J Neurol Surg A Cent Eur Neurosurg. 2017;78(2):180-90. https://doi.org/10.1055/s-0036-1592158.

9. Seifo N, Cassie H, Radford JR, Innes NPT. Silver diamine fluoride for managing carious lesions: an umbrella review. BMC Oral Health. 2019;19(1):145. https://doi.org/10.1186/s12903-019-0830-5.

10. Aromataris E, Fernandez R, Godfrey CM, Holly C, Khalil H, Tungpunkom P. Summarizing systematic reviews: methodological development, conduct and reporting of an umbrella review approach. Int J Evid Based Healthc. 2015;13(3):132-40. https://doi.org/10.1097/XEB.0000000000000055.

11. Balkau B, Eschwege E. Risk factors and their identification second part: study designs for identification of risk factors. Diabete Metab. 1995;21(3):225-31.

12. Clarivate. Thomson Reuters Web of Knowledge website; 2020. https://clarivate.com/webofsciencegroup/solutions/web-of-science/.

13. Apóstolo J, Cooke R, Bobrowicz-Campos E, Santana S, Marcucci M, Cano A, et al. Predicting risk and outcomes for frail older adults: an umbrella review of frailty screening tools. JBI Database System Rev Implement Rep. 2017 Apr; 15(4): 1154-208. https://doi.org/10.11124/JBISRIR-2016-003018.

14. Belbasis L, Bellou V, Evangelou E. Environmental Risk Factors and Amyotrophic Lateral Sclerosis: An Umbrella Review and Critical Assessment of Current Evidence from Systematic Reviews and Meta-Analyses of Observational Studies. Neuroepidemiology. 2016;46(2):96-105. https://doi.org/ 10.1159/000443146.

15. Belbasis L, Bellou V, Evangelou E, loannidis JP, Tzoulaki I. Environmental risk factors and multiple sclerosis: an umbrella review of systematic reviews and meta-analyses. Lancet Neurol. 2015;14(3):263-73. https://doi.org/10.1016/S1474-4422(14)70267-4.

16. Belbasis L, Dosis V, Evangelou E. Elucidating the environmental risk factors for rheumatic diseases: An umbrella review of meta-analyses. Int J Rheum Dis. 2018;21(8):1514- https://doi.org/24.10.1111/1756$185 X .13356$. 
17. Belbasis L, Köhler CA, Stefanis N, Stubbs B, van Os J, Vieta E, et al. Risk factors and peripheral biomarkers for schizophrenia spectrum disorders: an umbrella review of meta-analyses. Acta Psychiatr

Scand. 2018;137(2):88-97. https://doi.org/10.1111/acps.12847.

18. Belbasis L, Mavrogiannis MC, Emfietzoglou M, Evangelou E. Environmental factors, serum biomarkers and risk of atrial fibrillation: an exposure-wide umbrella review of meta-analyses. Eur $J$

Epidemiol. 2020;35(3):223-39. https://doi.org/10.1007/s10654-020-00618-3.

19. Belbasis L, Savvidou MD, Kanu C, Evangelou E, Tzoulaki I. Birth weight in relation to health and disease in later life: an umbrella review of systematic reviews and meta-analyses. BMC Med. 2016;14(1):147. https://doi.org/10.1186/s12916-016-0692-5.

20. Belbasis L, Stefanaki I, Stratigos AJ, Evangelou E. Non-genetic risk factors for cutaneous melanoma and keratinocyte skin cancers: An umbrella review of meta-analyses. J Dermatol Sci. 2016;84(3):330-9. https://doi.org/10.1016/j.jdermsci.2016.09.003.

21. Bellou V, Belbasis L, Konstantinidis AK, Evangelou E. Elucidating the risk factors for chronic obstructive pulmonary disease: an umbrella review of meta-analyses. Int J Tuberc Lung Dis. 2019;23(1):58-66. https://doi.org/10.5588/ijtld.18.0228.

22. Bellou V, Belbasis L, Tzoulaki I, Evangelou E. Risk factors for type 2 diabetes mellitus: An exposure-wide umbrella review of meta-analyses. PLoS One. 2018;13(3):e0194127.

https://doi.org/10.1371/journal.pone.0194127.

23. Bellou V, Belbasis L, Tzoulaki I, Evangelou E, loannidis JP. Environmental risk factors and Parkinson's disease: An umbrella review of meta-analyses. Parkinsonism Relat Disord. 2016;23:1-9.

https://doi.org/1016/j.parkreldis.2015.12.008.

24. Bellou V, Belbasis L, Tzoulaki I, Middleton LT, Ioannidis JPA, Evangelou E. Systematic evaluation of the associations between environmental risk factors and dementia: An umbrella review of systematic reviews and meta-analyses. Alzheimers Dement. 2017;13(4):406-18. https://doi.org/10.1016/j.jalz.2016.07.152.

25. Bortolato B, Köhler CA, Evangelou E, León-Caballero J, Solmi M, Stubbs B, et al. Systematic assessment of environmental risk factors for bipolar disorder: an umbrella review of systematic reviews and meta-analyses. Bipolar Disord. 2017;19(2):84-96. https://doi.org/10.1111/bdi.12490.

26. Bouras E, Karakioulaki M, Bougioukas KI, Aivaliotis M, Tzimagiorgis G, Chourdakis M. Gene promoter methylation and cancer: An umbrella review. Gene. 2019;710:333-40.

https://doi.org/10.1016/j.gene.2019.06.023.

27. Campbell JM, Bateman E, Peters M, Bowen JM, Keefe DM, Stephenson MD. Fluoropyrimidine and platinum toxicity pharmacogenetics: an umbrella review of systematic reviews and meta-analyses.

Pharmacogenomics. 2016;17(4):435-51. https://doi.org/10.2217/pgs.15.180.

28. Campbell JM, Bateman E, Stephenson MD, Bowen JM, Keefe DM, Peters MD. Methotrexate-induced toxicity pharmacogenetics: an umbrella review of systematic reviews and meta-analyses. Cancer Chemother Pharmacol. 2016;78(1):27-39. https://doi.org/10.1007/s00280-016-3043-5.

29. Campbell JM, Stephenson MD, Bateman E, Peters MD, Keefe DM, Bowen JM. Irinotecan-induced toxicity pharmacogenetics: an umbrella review of systematic reviews and meta-analyses. Pharmacogenomics J. 2017;17(1):21-8. https://doi.org/10.1038/tpj.2016.58.

30. Carvalho AF, Köhler CA, Fernandes BS, Quevedo J, Miskowiak KW, Brunoni AR, et al. Bias in emerging biomarkers for bipolar disorder. Psychol Med. 2016;46(11):2287-97. 
https://doi.org/10.1017/S0033291716000957.

31. Cupp M, Cariolou M, Tzoulaki I, Evangelos E, Berlanga-Taylor A. Neutrophil counts and cancer prognosis: An umbrella review of systematic reviews and meta-analyses of observational studies. bioRxiv. 2018. https://doi.org/10.1101/330076.

32. Fullana MA, Tortella-Feliu M, Fernández de la Cruz L, Chamorro J, Pérez-Vigil A, loannidis JPA, et al. Risk and protective factors for anxiety and obsessive-compulsive disorders: an umbrella review of systematic reviews and meta-analyses. Psychol Med. 2019:1-16. https://doi.org/10.1017/S0033291719001247.

33. Giannakou K, Evangelou E, Papatheodorou SI. Genetic and non-genetic risk factors for pre-eclampsia: umbrella review of systematic reviews and meta-analyses of observational studies. Ultrasound Obstet Gynecol. 2018;51(6):720-30. https://doi.org/10.1002/uog.18959.

34. Giannakou K, Evangelou E, Yiallouros P, Christophi CA, Middleton N, Papatheodorou E, et al. Risk factors for gestational diabetes: An umbrella review of meta-analyses of observational studies. PLoS One. 2019;14(4):e0215372. https://doi.org/10.1371/journal.pone.0215372.

35. Grabovac I, Veronese N, Stefanac S, Haider S, Jackson SE, Koyanagi A, et al. Human Immunodeficiency Virus Infection and Diverse Physical Health Outcomes: An Umbrella Review of Meta-analyses of Observational Studies. Clin Infect Dis. 2020;70(9):1809-15. https://doi.org/10.1093/cid/ciz539.

36. Hossain MM, Khan N, Sultana A, Ma P, McKyer ELJ, Ahmed HU, et al. Prevalence of comorbid psychiatric disorders among people with autism spectrum disorder: An umbrella review of systematic reviews and metaanalyses. Psychiatry Res. 2020;287:112922.

37. Hossain MM, Purohit N, Sultana A, Ma P, McKyer ELJ, Ahmed HU. Prevalence of mental disorders in South Asia: An umbrella review of systematic reviews and meta-analyses. Asian J Psychiatr. 2020;51:102041.

38. Hutchens BF, Kearney J. Risk Factors for Postpartum Depression: An Umbrella Review. J Midwifery Womens Health. 2020;65(1):96-108. https://doi.org/10.1111/jmwh.13067.

39. Kim JY, Son MJ, Son CY, Radua J, Eisenhut M, Gressier F, et al. Environmental risk factors and biomarkers for autism spectrum disorder: an umbrella review of the evidence. Lancet Psychiatry. 2019;6(7):590-600. https://doi.org/10.1016/S2215-0366(19)30181-6.

40. Li L, Tan J, Liu L, Li J, Chen G, Chen M, et al. Association between H. pylori infection and health Outcomes: an umbrella review of systematic reviews and meta-analyses. BMJ Open. 2020;10(1):e031951. https://doi.org/10.1136/bmjopen-2019-031951.

41. Lucaroni F, Cicciarella Modica D, Macino M, Palombi L, Abbondanzieri A, Agosti G, et al. Can risk be predicted? An umbrella systematic review of current risk prediction models for cardiovascular diseases, diabetes and hypertension. BMJ Open. 2019;9(12):e030234. https://doi.org/10.1136/bmjopen-2019-030234.

42. Lucaroni F, Morciano L, Rizzo G, F DA, Buonuomo E, Palombi L, et al. Biomarkers for predicting spontaneous preterm birth: an umbrella systematic review. J Matern Fetal Neonatal Med. 2018;31(6):726-34. https://doi.org/10.1080/14767058.2017.1297404.

43. Machado MO, Veronese N, Sanches M, Stubbs B, Koyanagi A, Thompson T, et al. The association of depression and all-cause and cause-specific mortality: an umbrella review of systematic reviews and metaanalyses. BMC Med. 2018;16(1):112. https://doi.org/10.1186/s12916-018-1101-z.

44. O'Sullivan JW, Muntinga T, Grigg S, loannidis JPA. Prevalence and outcomes of incidental imaging findings: umbrella review. BMJ. 2018;361:k2387. https://doi.org/10.1136/bmj.k2387. 
45. Parreira P, Maher CG, Steffens D, Hancock MJ, Ferreira ML. Risk factors for low back pain and sciatica: an umbrella review. Spine J. 2018;18(9):1715-21. https://doi.org/10.1016/j.spinee.2018.05.018

46. Piovani D, Danese S, Peyrin-Biroulet L, Nikolopoulos GK, Lytras T, Bonovas S. Environmental Risk Factors for Inflammatory Bowel Diseases: An Umbrella Review of Meta-analyses. Gastroenterology. 2019;157(3):64759.e4. https://doi.org/10.1053/j.gastro.2019.04.016.

47. Radua J, Ramella-Cravaro V, loannidis JPA, Reichenberg A, Phiphopthatsanee N, Amir T, et al. What causes psychosis? An umbrella review of risk and protective factors. World Psychiatry. 2018;17(1):49-66. https://doi.org/10.1002/wps.20490.

48. Raglan O, Kalliala I, Markozannes G, Cividini S, Gunter MJ, Nautiyal J, et al. Risk factors for endometrial cancer: An umbrella review of the literature. Int J Cancer. 2019;145(7):1719-30. https://doi.org/10.1002/ijc.31961.

49. Smith L, Luchini C, Demurtas J, Soysal P, Stubbs B, Hamer M, et al. Telomere length and health outcomes: An umbrella review of systematic reviews and meta-analyses of observational studies. Ageing Res Rev. 2019;51:1-10. https://doi.org/10.1016/j.arr.2019.02.003.

50. Tortella-Feliu M, Fullana MA, Pérez-Vigil A, Torres X, Chamorro J, Littarelli SA, et al. Risk factors for posttraumatic stress disorder: An umbrella review of systematic reviews and meta-analyses. Neurosci Biobehav Rev. 2019;107:154-65. https://doi.org/10.1016/j.neubiorev.2019.09.013.

51. Van Der Burg N, Bakker PR, Van Os J, Van Harten P, Al Hadithy A. The genetics of drug-related movement disorders an umbrella review of meta-analyses. Schizophrenia Bulletin. 2018;44:S295. https://doi.org/10.1038/s41380-020-0660-5.

52. Veronese N, Demurtas J, Soysal P, Smith L, Torbahn G, Schoene D, et al. Sarcopenia and health-related outcomes: an umbrella review of observational studies. European Geriatric Medicine. 2019;10(6):853-62. https://doi.org/10.1007/s41999-019-00233-w.

53. Yang T, Li X, Montazeri Z, Little J, Farrington SM, loannidis JPA, et al. Gene-environment interactions and colorectal cancer risk: An umbrella review of systematic reviews and meta-analyses of observational studies. Int J Cancer. 2019;145(9):2315-29. https://doi.org/10.1002/ijc.32057.

54. Zhou C, Zhong X, Song Y, Shi J, Wu Z, Guo Z, et al. Prognostic Biomarkers for Gastric Cancer: An Umbrella Review of the Evidence. Front Oncol. 2019;9:1321. https://doi.org/10.3389/fonc.2019.01321.

55. Safron M, Cislak A, Gaspar T, Luszczynska A. Effects of school-based interventions targeting obesity-related behaviors and body weight change: a systematic umbrella review. Behav Med. 2011;37(1):15-25. https://doi.org/10.1080/08964289.2010.543194.

56. Contopoulos-loannidis DG, loannidis JP. Claims for improved survival from systemic corticosteroids in diverse conditions: an umbrella review. Eur J Clin Invest. 2012;42(3):233-44. https://doi.org/10.1111/j.13652362.2011.02584.x.

57. Doufas AG, Panagiotou OA, loannidis JP. Concordance of sleep and pain outcomes of diverse interventions: an umbrella review. PLoS One. 2012;7(7):e40891. https://doi.org/10.1371/journal.pone.0040891.

58. Kumar S, Beaton K, Hughes T. The effectiveness of massage therapy for the treatment of nonspecific low back pain: a systematic review of systematic reviews. Int J Gen Med. 2013;6:733-41. https://doi.org/10.2147/IJGM.S50243.

59. Mossialos E, Naci H, Courtin E. Expanding the role of community pharmacists: policymaking in the absence of policy-relevant evidence?. Health Policy. 2013;111(2):135-48. 
https://doi.org/10.1016/j.healthpol.2013.04.003.

60. Bidonde J, Busch AJ, Bath B, Milosavljevic S. Exercise for adults with fibromyalgia: an umbrella systematic review with synthesis of best evidence. Curr Rheumatol Rev. 2014;10(1):45-79.

https://doi.org/10.2174/1573403x10666140914155304.

61. Tonelli AR, Zein J, Adams J, loannidis JP. Effects of interventions on survival in acute respiratory distress syndrome: an umbrella review of 159 published randomized trials and 29 meta-analyses. Intensive Care Med. 2014;40(6):769-87. https://doi.org/10.1007/s00134-014-3272-1.

62. Horodyska K, Luszczynska A, Hayes CB, O'Shea MP, Langøien LJ, Roos G, et al. Implementation conditions for diet and physical activity interventions and policies: an umbrella review. BMC Public Health. 2015;15:1250. https://doi.org/10.1186/s12889-015-2585-5.

63. Horodyska K, Luszczynska A, van den Berg M, Hendriksen M, Roos G, De Bourdeaudhuij I, et al. Good practice characteristics of diet and physical activity interventions and policies: an umbrella review. BMC Public Health. 2015;15:19. https://doi.org/10.1186/s12889-015-1354-9.

64. Stubbs B, Brefka S, Denkinger MD. What Works to Prevent Falls in Community-Dwelling Older Adults? Umbrella Review of Meta-analyses of Randomized Controlled Trials. Phys Ther. 2015;95(8):1095-110. https://doi.org/10.2522/ptj.20140461.

65. Stubbs B, Denkinger MD, Brefka S, Dallmeier D. What works to prevent falls in older adults dwelling in long term care facilities and hospitals? An umbrella review of meta-analyses of randomised controlled trials. Maturitas. 2015;81(3):335-42. https://doi.org/10.1016/j.maturitas.2015.03.026.

66. Barbosa Filho VC, Minatto G, Mota J, Silva KS, de Campos W, Lopes Ada S. Promoting physical activity for children and adolescents in low- and middle-income countries: An umbrella systematic review: A review on promoting physical activity in LMIC. Prev Med. 2016;88:115-26.

https://doi.org/10.1016/j.ypmed.2016.03.025.

67. Botero JE, Rodríguez C, Agudelo-Suarez AA. Periodontal treatment and glycaemic control in patients with diabetes and periodontitis: an umbrella review. Aust Dent J. 2016;61(2):134-48. https://doi.org/10.1111/adj.12413.

68. Catalan-Matamoros D, Gomez-Conesa A, Stubbs B, Vancampfort D. Exercise improves depressive symptoms in older adults: An umbrella review of systematic reviews and meta-analyses. Psychiatry Res. 2016;244:2029. https://doi.org/10.1016/j.psychres.2016.07.028.

69. Conn VS, Coon Sells TG. Effectiveness of Interventions to Increase Physical Activity Among Minority Populations: An Umbrella Review. J Natl Med Assoc. 2016;108(1):54-68.

https://doi.org/10.1016/j.jnma.2015.12.008.

70. D’Souza V, Daudt H, Kazanjian A. Survivorship care plans for people with colorectal cancer: Do they reflect the research evidence? Current Oncology. 2016;23(5):e488-98. https://doi.org/10.3747/co.23.3114.

71. Damery S, Flanagan S, Combes G. Does integrated care reduce hospital activity for patients with chronic diseases? An umbrella review of systematic reviews. BMJ Open. 2016;6(11):e011952. https://doi.org/10.1136/bmjopen-2016-011952.

72. Cant RP, Cooper SJ. Use of simulation-based learning in undergraduate nurse education: An umbrella systematic review. Nurse Educ Today. 2017;49:63-71. https://doi.org/10.1016/j.nedt.2016.11.015.

73. Dragioti E, Karathanos V, Gerdle B, Evangelou E. Does psychotherapy work? An umbrella review of metaanalyses of randomized controlled trials. Acta Psychiatr Scand. 2017;136(3):236-46. 
https://doi.org/10.1111/acps.12713.

74. Elliott J, Kelly SE, Johnston A, Skidmore B, Gomes T, Wells GA. Allergen immunotherapy for the treatment of allergic rhinitis and/or asthma: an umbrella review. CMAJ Open. 2017;5(2):E373-85.

https://doi.org/10.9778/cmajo.20160066.

75. Flanagan S, Damery S, Combes G. The effectiveness of integrated care interventions in improving patient quality of life (QoL) for patients with chronic conditions. An overview of the systematic review evidence. Health Qual Life Outcomes. 2017;15(1):188. https://doi.org/10.1186/s12955-017-0765-y.

76. Liu XL, Shi Y, Willis K, Wu CJ, Johnson M. Health education for patients with acute coronary syndrome and type 2 diabetes mellitus: an umbrella review of systematic reviews and meta-analyses. BMJ Open. 2017;7(10):e016857. https://doi.org/10.1136/bmjopen-2017-016857.

77. McRae M. Therapeutic benefits of glutamine: An umbrella review of meta-analyses. Biomed Rep. 2017;6(5):576-584. https://doi.org/10.3892/br.2017.885.

78. McRae MP. Dietary Fiber Is Beneficial for the Prevention of Cardiovascular Disease: An Umbrella Review of Meta-analyses. J Chiropr Med. 2017;16(4):289-99. https://doi.org/10.1016/j.jcm.2017.05.005.

79. Pasanen T, Tolvanen S, Heinonen A, Kujala UM. Exercise therapy for functional capacity in chronic diseases: an overview of meta-analyses of randomised controlled trials. Br J Sports Med. 2017;51(20):1459-65. https://doi.org/10.1136/bjsports-2016-097132.

80. Rajjo T, Mohammed K, Alsawas M, Ahmed AT, Farah W, Asi N, et al. Treatment of Pediatric Obesity: An Umbrella Systematic Review. J Clin Endocrinol Metab. 2017;102(3):763-75. https://doi.org/10.1210/jc.20162574.

81. SmithBattle L, Loman DG, Chantamit OPC, Schneider JK. An umbrella review of meta-analyses of interventions to improve maternal outcomes for teen mothers. J Adolesc. 2017;59:97-111. https://doi.org/10.1016/j.adolescence.2017.05.022.

82. Turrini G, Purgato M, Ballette F, Nosè M, Ostuzzi G, Barbui C. Common mental disorders in asylum seekers and refugees: umbrella review of prevalence and intervention studies. Int J Ment Health Syst. 2017;11:51. https://doi.org/10.1186/s13033-017-0156-0.

83. Wolf A, Whiting D, Fazel S. Violence prevention in psychiatry: an umbrella review of interventions in general and forensic psychiatry. J Forens Psychiatry Psychol. 2017;28(5):659-73.

https://doi.org/10.1080/14789949.2017.1284886.

84. Befus D, Coeytaux RR, Goldstein KM, McDuffie JR, Shepherd-Banigan M, Goode AP, et al. Management of Menopause Symptoms with Acupuncture: An Umbrella Systematic Review and Meta-Analysis. J Altern Complement Med. 2018;24(4):314-23. https://doi.org/10.1089/acm.2016.0408.

85. Bonovas S, Pantavou K, Evripidou D, Bastiampillai AJ, Nikolopoulos GK, Peyrin-Biroulet L, et al. Safety of biological therapies in ulcerative colitis: An umbrella review of meta-analyses. Best Pract Res Clin Gastroenterol. 2018;32-33:43-7. https://doi.org/10.1016/j.bpg.2018.05.005.

86. Cheng H, Clymer JW, Sadeghirad B, Ferko NC, Cameron CG, Amaral JF. Performance of Harmonic devices in surgical oncology: an umbrella review of the evidence. World J Surg Oncol. 2018;16(1):2. https://doi.org/10.1186/s12957-017-1298-x.

87. Craike M, Wiesner G, Hilland TA, Bengoechea EG. Interventions to improve physical activity among socioeconomically disadvantaged groups: an umbrella review. Int J Behav Nutr Phys Act. 2018;15(1):43. https://doi.org/10.1186/s12966-018-0676-2.

Page 19/25 
88. de Oliveira-Neto OB, Barbosa FT, de Sousa-Rodrigues CF, de Lima FJC. Risk of bias assessment of systematic reviews regarding dental implant placement in smokers: An umbrella systematic review. J Prosthet Dent. 2018;120(2):198-203. https://doi.org/10.1016/j.prosdent.2017.12.026.

89. De Spiegeleer A, Beckwée D, Bautmans I, Petrovic M. Pharmacological Interventions to Improve Muscle Mass, Muscle Strength and Physical Performance in Older People: An Umbrella Review of Systematic Reviews and Meta-analyses. Drugs Aging. 2018;35(8):719-34. https://doi.org/10.1007/s40266-018-0566-y.

90. Dragioti E, Evangelou E, Larsson B, Gerdle B. Effectiveness of multidisciplinary programmes for clinical pain conditions: An umbrella review. J Rehabil Med. 2018;50(9):779-91. https://doi.org/10.2340/16501977-2377.

91. Ferreira RM, Duarte JA, Gonçalves RS. Non-pharmacological and non-surgical interventions to manage patients with knee osteoarthritis: An umbrella review. Acta Reumatol Port. 2018;43(3):182-200.

92. Fuller JT, Hartland MC, Maloney LT, Davison K. Therapeutic effects of aerobic and resistance exercises for cancer survivors: a systematic review of meta-analyses of clinical trials. Br J Sports Med. 2018;52(20):1311. https://doi.org/10.1136/bjsports-2017-098285.

93. Houzé B, El-Khatib H, Arbour C. Reprint of: Efficacy, tolerability, and safety of non-pharmacological therapies for chronic pain: An umbrella review on various CAM approaches. Prog Neuropsychopharmacol Biol Psychiatry. 2018;87(Pt B):307-21. https://doi.org/10.1016/j.pnpbp.2017.06.035.

94. Jadczak AD, Makwana N, Luscombe-Marsh N, Visvanathan R, Schultz TJ. Effectiveness of exercise interventions on physical function in community-dwelling frail older people: an umbrella review of systematic reviews. JBI Database System Rev Implement Rep. 2018;16(3):752-75. https://doi.org/10.11124/JBISRIR2017-003551.

95. Koretsi V, Eliades T, Papageorgiou SN. Oral Interventions for Obstructive Sleep Apnea. Dtsch Arzteb/ Int. 2018;115(12):200-7. https://doi.org/10.3238/arztebl.2018.0200.

96. Lipovec NC, Zerovnik S, Kos M. Pharmacy supported interventions at transitions of care: an umbrella review. Int J Clin Pharm. 2019;(4):831-852. https://doi.org/10.1007/s11096-019-00833-3.

97. Mamais I, Papadopoulos K, Lamnisos D, Stasinopoulos D. Effectiveness of Low Level Laser Therapy (LLLT) in the treatment of Lateral elbow tendinopathy (LET): an umbrella review. Laser Ther. 2018;27(3):174-86. https://doi.org/10.5978/islsm.27_18-0R-16.

98. Martin Ruiz E, Olry de Labry A, Epstein D. Primary prevention of cardiovascular disease: an umbrella review. An Sist Sanit Navar. 2018;41(3):355-69. https://doi.org/10.23938/ASSN.0316.

99. Martin-Saavedra JS, Vergara-Mendez LD, Talero-Gutiérrez C. Music is an effective intervention for the management of pain: An umbrella review. Complement Ther Clin Pract. 2018;32:103-14. https://doi.org/10.1016/j.ctcp.2018.06.003.

100. Merli M, Moscatelli M, Pagliaro U, Mariotti G, Merli I, Nieri M. Implant prosthetic rehabilitation in partially edentulous patients with bone atrophy. An umbrella review based on systematic reviews of randomised controlled trials. Eur J Oral Implantol. 2018;11(3):261-80.

101. Poscia A, Milovanovic S, La Milia DI, Duplaga M, Grysztar M, Landi F, et al. Effectiveness of nutritional interventions addressed to elderly persons: umbrella systematic review with meta-analysis. Eur J Public Health. 2018;28(2):275-83. https://doi.org/10.1093/eurpub/ckx199.

102. Rangel-Rincón LJ, Vivares-Builes AM, Botero JE, Agudelo-Suárez AA. An Umbrella Review Exploring the Effect of Periodontal Treatment in Pregnant Women on the Frequency of Adverse Obstetric Outcomes. J Evid Based Dent Pract. 2018;18(3):218-39. https://doi.org/10.1016/j.jebdp.2017.10.011. 
103. Solmi M, Köhler CA, Stubbs B, Koyanagi A, Bortolato B, Monaco F, et al. Environmental risk factors and nonpharmacological and nonsurgical interventions for obesity: An umbrella review of meta-analyses of cohort studies and randomized controlled trials. Eur J Clin Invest. 2018;48(12):e12982. https://doi.org/10.1111/eci.12982.

104. Andersson G, Carlbring P, Titov N, Lindefors N. Internet Interventions for Adults with Anxiety and Mood Disorders: A Narrative Umbrella Review of Recent Meta-Analyses. Can J Psychiatry. 2019;64(7):465-70. https://doi.org/10.1177/0706743719839381.

105. Andreeva-Gateva P, Chakar S. The place of trabectedin in the treatment of soft tissue sarcoma: an umbrella review of the level one evidence. Expert Opinion on Orphan Drugs. 2019;7(3):105-15. https://doi.org/10.1080/21678707.2019.1589449.

106. Angela S, Tullia SD, Giorgia F, Valter S, Teresa P. Occupational Therapy in Fatigue Management in Multiple Sclerosis: An Umbrella Review. Mult Scler Int. 2019; :2027947. https://doi.org/10.1155/2019/2027947.

107. Antonelli M, Donelli D, Firenzuoli F. Therapeutic efficacy of orally administered pollen for nonallergic diseases: An umbrella review. Phytother Res. 2019;33(11):2938-47. https://doi.org/10.1002/ptr.6484.

108. Ashor AW, Brown R, Keenan PD, Willis ND, Siervo M, Mathers JC. Limited evidence for a beneficial effect of vitamin $\mathrm{C}$ supplementation on biomarkers of cardiovascular diseases: an umbrella review of systematic reviews and meta-analyses. Nutr Res. 2019;61:1-12. https://doi.org/10.1016/j.nutres.2018.08.005.

109. Beckwée D, Delaere A, Aelbrecht S, Baert V, Beaudart C, Bruyere O, et al. Exercise Interventions for the Prevention and Treatment of Sarcopenia. A Systematic Umbrella Review. J Nutr Health Aging. 2019;23(6):494-502. https://doi.org/10.1007/s12603-019-1196-8.

110. Browne S, Minozzi S, Bellisario C, Sweeney MR, Susta D. Effectiveness of interventions aimed at improving dietary behaviours among people at higher risk of or with chronic non-communicable diseases: an overview of systematic reviews. Eur J Clin Nutr. 2019;73(1):9-23. https://doi.org/10.1038/s41430-018-0327-3.

111. Brunner R, Friesenbichler B, Casartelli NC, Bizzini M, Maffiuletti NA, Niedermann K. Effectiveness of multicomponent lower extremity injury prevention programmes in team-sport athletes: an umbrella review. $\mathrm{Br}$ J Sports Med. 2019;53(5):282-8.

112. Cebron Lipovec N, Zerovnik S, Kos M. Pharmacy-supported interventions at transitions of care: an umbrella review. Int J Clin Pharm. 2019;41(4):831-52. https://doi.org/10.1007/s11096-019-00833-3.

113. Chai LK, Collins C, May C, Brain K, Wong See D, Burrows T. Effectiveness of family-based weight management interventions for children with overweight and obesity: an umbrella review. JBI Database System Rev Implement Rep. 2019;17(7):1341-427. https://doi.org/10.11124/JBISRIR-2017-003695.

114. Chakranon P, Lai YK, Tang YW, Choudhary P, Khunti K, Lee SWH. Distal technology interventions in people with diabetes: an umbrella review of multiple health outcomes. Diabet Med. 2019;37(12):1966-76. https://doi.org/10.1111/dme.14156.

115. Cruciani M, Franchini M, Mengoli C, Marano G, Pati I, Masiello F, et al. Platelet-rich plasma for sports-related muscle, tendon and ligament injuries: an umbrella review. Blood Transfus. 2019;17(6):465-78. https://doi.org/10.2450/2019.0274-19.

116. Elliott J, Kelly SE, Bai Z, Liu W, Skidmore B, Boucher M, et al. Optimal Duration of Dual Antiplatelet Therapy Following Percutaneous Coronary Intervention: An Umbrella Review. Can J Cardiol. 2019;35(8):1039-46. https://doi.org/10.1016/j.cjca.2019.01.021.

Page $21 / 25$ 
117. Fusar-Poli P, Davies C, Solmi M, Brondino N, De Micheli A, Kotlicka-Antczak M, et al. Preventive Treatments for Psychosis: Umbrella Review (Just the Evidence). Front Psychiatry. 2019;10:764.

https://doi.org/10.3389/fpsyt.2019.00764.

118. Kampling H, Brendel LK, Mittag O. (Neuro)Psychological Interventions for Non-Motor Symptoms in the Treatment of Patients with Parkinson's Disease: a Systematic Umbrella Review. Neuropsychol Rev. 2019;29(2):166-80. https://doi.org/10.1007/s11065-019-09409-4.

119. Khan SU, Khan MU, Riaz H, Valavoor S, Zhao D, Vaughan L, et al. Effects of Nutritional Supplements and Dietary Interventions on Cardiovascular Outcomes: An Umbrella Review and Evidence Map. Ann Intern Med. 2019;171(3):190-8. https://doi.org/10.7326/M19-0341.

120. Kim JY, Lee KH, Eisenhut M, van der Vliet HJ, Kronbichler A, Jeong GH, et al. Efficacy of Cancer Immunotherapy: An Umbrella Review of Meta-analyses of Randomized Controlled Trials. Cancers (Basel). 2019;11(11):1801. https://doi.org/10.3390/cancers11111801.

121. Murao S, Yamakawa K. A Systematic Summary of Systematic Reviews on Anticoagulant Therapy in Sepsis. J Clin Med. 2019;8(11):1869. https://doi.org/10.3390/jcm8111869.

122. Salomè A, Sasso D'Elia T, Franchini G, Santilli V, Paolucci T. Occupational Therapy in Fatigue Management in Multiple Sclerosis: An Umbrella Review. Mult Scler Int. 2019;2019:2027947. https://doi.org/10.1155/2019/2027947.

123. Sharka $\mathrm{R}$, Abed H, Hector M. Oral health-related quality of life and satisfaction of edentulous patients using conventional complete dentures and implant-retained overdentures: An umbrella systematic review. Gerodontology. 2019;36(3):195-204. https://doi.org/10.1111/ger.12399.

124. Shi Y, Zhou S, Zheng Q, Huang Y, Hao P, Xu M, et al. Systematic reviews of pharmacological and nonpharmacological treatments for patients with chronic urticaria: An umbrella systematic review. Medicine (Baltimore). 2019;98(20):e15711. https://doi.org/10.1097/MD.0000000000015711

125. Siqueira TC, Dominski FH, Andrade A. Effects of exercise in people with haemophilia: An umbrella review of systematic reviews and meta-analyses. Haemophilia. 2019;25(6):928-37. https://doi.org/10.1111/hae.13868.

126. Abdulrhim S, Sankaralingam S, Ibrahim MIM, Awaisu A. The impact of pharmacist care on diabetes outcomes in primary care settings: An umbrella review of published systematic reviews. Prim Care Diabetes. 2020.14(5):393-400. https://doi.org/10.1016/j.pcd.2019.12.007.

127. Andrade A, Dominski FH, Sieczkowska SM. What we already know about the effects of exercise in patients with fibromyalgia: An umbrella review. Semin Arthritis Rheum. 2020.50(6):1465-80. https://doi.org/10.1016/j.semarthrit.2020.02.003.

128. Barbui C, Purgato M, Abdulmalik J, Acarturk C, Eaton J, Gastaldon C, et al. Efficacy of psychosocial interventions for mental health outcomes in low-income and middle-income countries: an umbrella review. Lancet Psychiatry. 2020;7(2):162-72. https://doi.org/10.1016/S2215-0366(19)30511-5.

129. Biondi-Zoccai G, Antonazzo B, Giordano A, Versaci F, Frati G, Ronzoni S, et al. Oral antiplatelet therapy in the elderly undergoing percutaneous coronary intervention: an umbrella review. J Thorac Dis. 2020;12(4):165664. https://doi.org/10.21037/jtd.2019.12.87.

130. Dietz P, Reichel JL, Edelmann D, Werner AM, Tibubos AN, Schäfer M, et al. A Systematic Umbrella Review on the Epidemiology of Modifiable Health Influencing Factors and on Health Promoting Interventions Among University Students. Front Public Health. 2020;8:137. https://doi.org/10.3389/fpubh.2020.00137. 
131. Dinu M, Pagliai G, Angelino D, Rosi A, Dall'Asta M, Bresciani L, et al. Effects of Popular Diets on Anthropometric and Cardiometabolic Parameters: An Umbrella Review of Meta-Analyses of Randomized Controlled Trials. Adv Nutr. 2020;11(4):815-33. https://doi.org/10.1093/advances/nmaa006.

132. Grgic J, Grgic I, Pickering C, Schoenfeld BJ, Bishop DJ, Pedisic Z. Wake up and smell the coffee: caffeine supplementation and exercise performance-an umbrella review of 21 published meta-analyses. Br J Sports Med. 2020;54(11):681-8. https://doi.org/10.1136/bjsports-2018-100278.

133. Jarvis MA, Padmanabhanunni A, Balakrishna Y, Chipps J. The effectiveness of interventions addressing loneliness in older persons: An umbrella review. IJANS. 2020;12. https://doi.org/10.1016/j.ijans.2019.100177.

134. Jiang M, Ma Y, Yun B, Wang Q, Huang C, Han L. Exercise for fatigue in breast cancer patients: An umbrella review of systematic reviews. Int J Nurs Sci. 2020;7(2):248-54. https://doi.org/10.1016/j.ijnss.2020.03.001.

135. Khalil H, Ellwood L, Lord H, Fernandez R. Pharmacological Treatment for Obesity in Adults: An Umbrella Review. Ann Pharmacother. 2020 ;54(7):691-705. https://doi.org/10.1177/1060028019898912.

136. Low TL, Choo FN, Tan SM. The efficacy of melatonin and melatonin agonists in insomnia - An umbrella review. J Psychiatr Res. 2020;121:10-23. https://doi.org/10.1016/j.jpsychires.2019.10.022.

137. Moore SA, Hrisos N, Errington L, Rochester L, Rodgers H, Witham M, et al. Exercise as a treatment for sarcopenia: an umbrella review of systematic review evidence. Physiotherapy. 2020;107:189-201. https://doi.org/10.1016/j.physio.2019.08.005.

138. Nagendrababu V, Duncan HF, Whitworth J, Nekoofar MH, Pulikkotil SJ, Veettil SK, et al. Is articaine more effective than lidocaine in patients with irreversible pulpitis? An umbrella review. Int Endod J. 2020;53(2):20013. https://doi.org/10.1111/iej.13215.

139. Newman TV, San-Juan-Rodriguez A, Parekh N, Swart ECS, Klein-Fedyshin M, Shrank WH, et al. Impact of community pharmacist-led interventions in chronic disease management on clinical, utilization, and economic outcomes: An umbrella review. Res Social Adm Pharm. 2020 ;16(9):1155-1165. https://doi.org/10.1016/j.sapharm.2019.12.016.

140. Pieters L, Lewis J, Kuppens K, Jochems J, Bruijstens T, Joossens L, et al. An Update of Systematic Reviews Examining the Effectiveness of Conservative Physical Therapy Interventions for Subacromial Shoulder Pain. J Orthop Sports Phys Ther. 2020;50(3):131-41. https://doi.org/10.2519/jospt.2020.8498.

141. Smith J, Ali P, Birks Y, Curtis P, Fairbrother H, Kirk S, et al. Umbrella review of family-focused care interventions supporting families where a family member has a long-term condition. J Adv Nurs. 2020. https://doi.org/10.1111/jan.14367.

142. Timpel P, Oswald S, Schwarz PEH, Harst L. Mapping the Evidence on the Effectiveness of Telemedicine Interventions in Diabetes, Dyslipidemia, and Hypertension: An Umbrella Review of Systematic Reviews and Meta-Analyses. J Med Internet Res. 2020;22(3):e16791. https://doi.org/10.2196/16791.

143. Ton J, Perry D, Thomas B, Allan GM, Lindblad AJ, McCormack J, et al. PEER umbrella systematic review of systematic reviews: Management of osteoarthritis in primary care. Can Fam Physician. 2020;66(3):e89-98.

144. Van IMH, Bakermans-Kranenburg MJ, Coughlan B, Reijman S. Annual Research Review: Umbrella synthesis of meta-analyses on child maltreatment antecedents and interventions: differential susceptibility perspective on risk and resilience. J Child Psychol Psychiatry. 2020;61(3):272-90. https://doi.org/10.1111/jcpp.13147.

145. Zhianfar L, Nadrian H, Shaghaghi A. Enhancement of Adherence to Therapeutic and Lifestyle Recommendations Among Hemodialysis Patients: An Umbrella Review of Interventional Strategies. Ther Clin 
Risk Manag. 2020;16:233-43. https://doi.org/10.2147/TCRM.S240125.

146. Zhu J, Yu X, Zheng Y, Li J, Wang Y, Lin Y, et al. Association of glucose-lowering medications with cardiovascular outcomes: an umbrella review and evidence map. Lancet Diabetes Endocrinol. 2020;8(3):192205. https://doi.org/10.1016/S2213-8587(19)30422-X.

147. Balshem H, Helfand M, Schünemann HJ, Oxman AD, Kunz R, Brozek J, et al. GRADE guidelines: 3. Rating the quality of evidence. J Clin Epidemiol. 2011;64(4):401-6. https://doi.org/10.1016/j.jclinepi.2010.07.015.

148. Schlesinger S, Schwingshackl L, Neuenschwander M, Barbaresko J. A critical reflection on the grading of the certainty of evidence in umbrella reviews. Eur J Epidemiol. 2019;34(9):889-90.

https://doi.org/10.1007/s10654-019-00531-4.

\section{Figures}

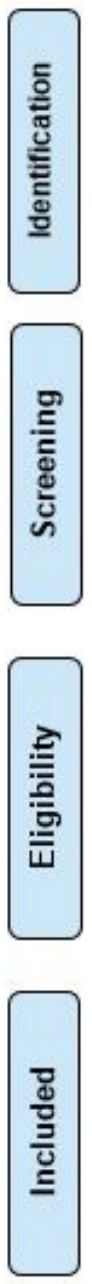

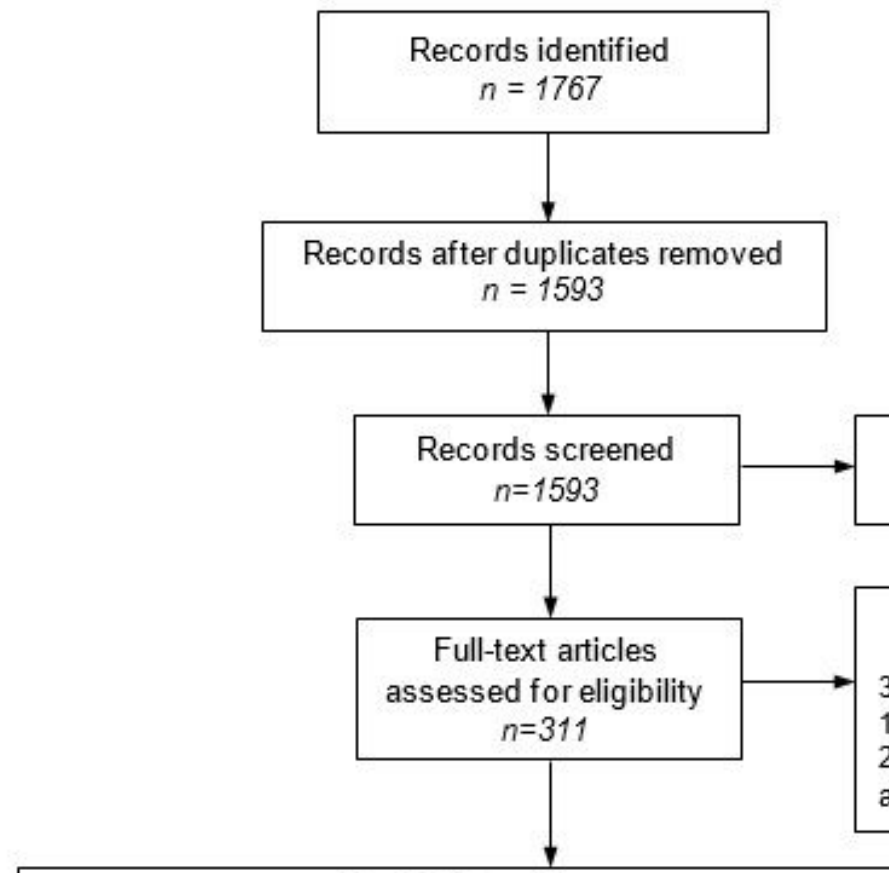

Total 253 studies

UR of Intervention or therapy (Prevention and treatment) $n=203$ UR of Non-intervention/therapy $n=50$

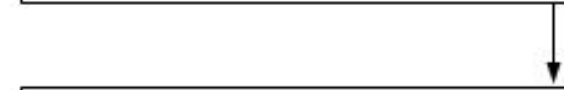

Total 138 studies

UR of intervention/therapy with MA of experimental studies $n=96$ UR of Non-intervention/therapy $n=42$
Records excluded $n=1282$

Full-text articles excluded $n=58$

37 UR that notincluded meta-analysis 19 Conference abstract and poster information 2 UR that further performed network metaanalysis

$\rightarrow \begin{gathered}\text { Excluded studies } n=115 \\ 108 \text { Not an UR of meta-analysis of } \\ \text { Intervention/therapy that } \\ \text { included the experimentalstudies }\end{gathered}$

\section{Figure 1}

Evidence search and selection 


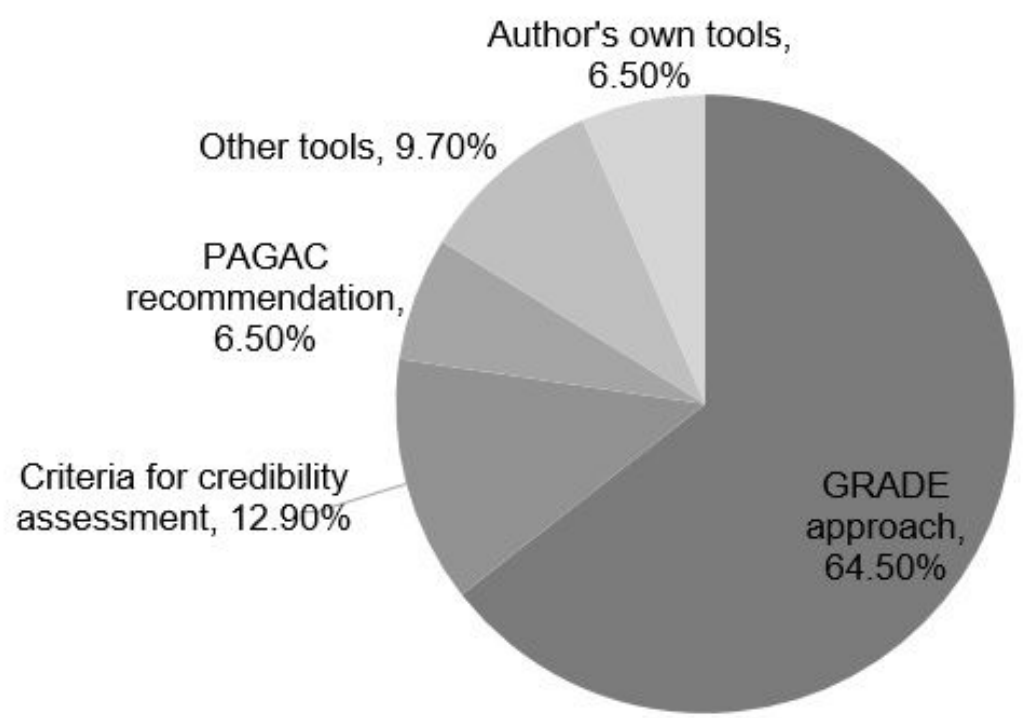

Figure 2A Methodological approaches for certainty of evidence assessment

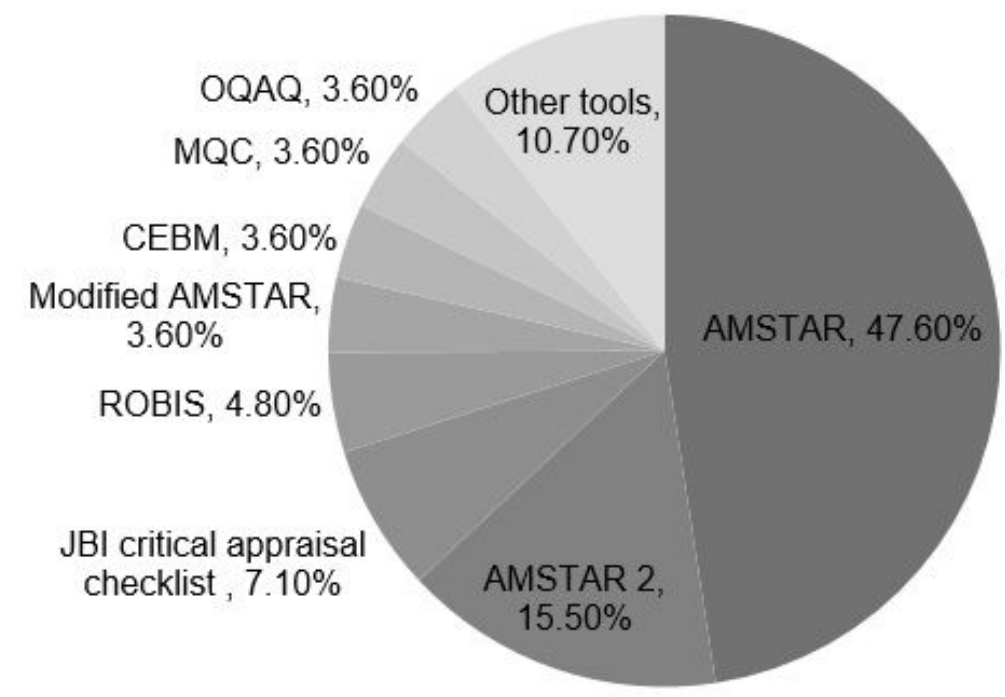

Figure 2B Methodological approaches for methodological quality assessment

Figure 2

Percent used of methodological approaches for certainty and methodological quality assessment

\section{Supplementary Files}

This is a list of supplementary files associated with this preprint. Click to download.

- SupplementaryfileURcertainty20200516.docx 